\title{
The absence of MyD88 has no effect on the induction of alternatively activated macrophage during Fasciola hepatica infection
}

\author{
HongLin Luo ${ }^{1 *}$, Weiyi Huang ${ }^{2}$, Dongying Wang ${ }^{2,3}$, Haoju Wang ${ }^{1}$ and Kui Nie ${ }^{1}$
}

\begin{abstract}
Background: Alternatively activated macrophages (AAM $\varphi$ ) play important roles in allergies and responses to parasitic infections. However, whether signaling through toll-like receptors (TLRs) plays any role in AAM $\varphi$ induction when young Fasciola hepatica penetrates the liver capsule and migrates through the liver tissue is still unclear.

Results: The data show that the lack of myeloid differentiation factor 88 (MyD88) has no effect on the AAM $\varphi$ derived from the bone marrow (BMM $)$ in vitro and does not impair the mRNA expression of arginase-1, resistinlike molecule (RELM $\alpha$ ), and Ym1 in BMM $\varphi$ s. The Th2 cytokine production bias in splenocytes was not significantly altered in F. hepatica-infected mice in the absence of MyD88 in vitro and in the pleural cavity lavage in vivo. In addition, MyD88-deficiency has no effect on the arginase production of the $F$. hepatica elicited macrophages (Fe $M \varphi s)$, production of RELM $\alpha$ and $Y m 1$ proteins and mRNA expression of $Y m 1$ and RELM $\alpha$ of macrophages in the peritoneal cavity 6 weeks post F. hepatica infection.
\end{abstract}

Conclusions: The absence of MyD88 has no effect on presence of AAM $\varphi$ weeks post $F$. hepatica infection.

\section{Background}

Macrophages are highly plastic cells that respond to diverse environments by altering their phenotype and physiology $[1,2]$ and play important roles in both innate and adaptive immunity. Currently, macrophages are classified under two phenotypes, classically activated macrophages (CAM $\Phi)$ and alternatively activated macrophages (AАM $\Phi)$. САM $\Phi$ are induced by interferon-gamma (IFN- $\gamma$ ) and lipopolysaccharide (LPS), whereas induction of the AАMФ phenotype is associated with various stimuli, such as IL-4/IL-13, IL-10, immunocomplexes, and glucocorticoids [2]. The most widely studied stimuli for generating AAMФ is treatment with IL-4/IL-13 [1,3]. Although IL-4/IL-13 signaling are essential to the presence of АAM $\Phi$ and both cytokines have many overlapping activities on macrophages, they exhibit distinct functions because of their specific receptor subunits aside from their shared common alpha chain [4]. However, this does not alter the

\footnotetext{
* Correspondence: Ihl200296@yahoo.cn

'Laboratory of Infection \& Immunology Research, College of Animal Science \& Technology, Southwest University, Chongqing, China

Full list of author information is available at the end of the article
}

fact that a Th2-dominated environment is critical for AAM $\Phi$ induction [5-7]. All helminths have been demonstrated to induce profound Th2 responses, which are characterized by the production of IL-4, IL-5, IL-9, IL-10, and IL- 13 by CD4 $4^{+} \mathrm{T}$ cells [8], and this Th2dominated cytokine profile is associated with the presence of the ААМФ phenotype (such as in Schistosoma mansoni [9], Taenia crassiceps [10], Brugia malayi [11], Heligmosomoides polygyrus [12], Nippostrongylus brasiliensis [13], and F. hepatica infection [14,15], and so forth). AАM $\Phi$ are increasingly recognized as a key effector arm of the Th2 immunity, but their real function in various helminth infections has not been illustrated and is likely to be diverse. However, discovery of molecular markers of AAM $\Phi$, such as mannose receptor (CD206), IL-10, arginase -1 (instead of inducible nitric oxide), resistin-like molecule (RELM $\alpha$ ), and Ym1 [6,16-19], made the identification of AAM $\Phi$ possible. Among them, three most abundant IL-4/IL-13 dependent genes: Ym1, a member of the family 18 chitinases family but with no chitinolytic activity [20], RELM $\alpha$, was described as FIZZ1 [21], and is identified as a cysteine-rich molecule associated with resistin that is involved in glucose 
metabolism [22]. Arginase 1 plays a role in the regulation of nitric oxide (NO) production by competing with iNOS for substrate L-arginine [23], suppression of T cell responses via L-arginine depletion [24] and has been currently accepted as a molecular signature for AAMФ. However, the functions of АAM $\Phi$ in helminth infections have not been fully illustrated. Questions such as whether AAMФ promotes helminth killing or expulsion, whether alternative activation requires anti-worm effector function, or whether signaling TLRs play a role in AAM $\Phi$ induction, have not been fully answered.

In the current study, the role of TLRs in AAMФ induction during $F$. hepatica infection, which has been observed to produce Th2-dominated responses in both mice and the natural ruminant hosts $[14,15]$ is investigated using MyD88-deficient mice.

TLRs are pattern recognition receptors (PRRs) that recognize different pathogen-associated molecular patterns (PAMPs) [25]. TLR signaling is mostly MyD88dependent $[26,27]$ except for TLR3 signaling, which requires a TRIF adaptor [26,27]. Mice lacking MyD88 cannot respond to LPS [28]. The absence of MyD88 has been demonstrated to have no effect on the augmentation of Th2 responses [29,30], which indicates that Th2 responses are elicited in a MyD88-independent manner. However, contrary results have also demonstrated that TLR signaling plays a role in Th2 responses [31]. Aside from the required Th2 environment, especially with IL4/IL-13, the determinants of the AAMФ phenotype remain unclear. For $F$. hepatica infection, whether TLR signaling is required for AAMФ induction is unknown. Therefore, whether AAM $\Phi$ could be induced without MyD88 and whether TLR signals affect AAM $\varphi$ activation were investigated.

\section{Results}

Lacking of MyD88 has no impact on the presence of AAM $\Phi$ derived from bone marrow

To determine whether MyD88 signaling is required for AAM $\Phi$ induction, investigations were made to determine whether BMM $\varphi$, cultured from both WT and MyD88 knockout mice, could be activated through this approach. This is based on the fact that arginase- 1 upregulation, which is generally associated with Th2 cytokines, such as IL-4 [32], is a feature of AAMФs. As a control, iNOS, the enzyme associated with CAMФs, was also detected [33]. BMM $\varphi$ s were treated with LPS and IFN- $\gamma$, either together or separately, or with media alone for 20-24 h after overnight treatment with or without IL-4. Subsequently, arginase-1 and iNOS enzyme activity were measured (Figure 1). The results show both WT and MyD88-/- BMM $\varphi$ cells displayed arginase activity in response to IL-4 compared with the cells without IL-4 stimulation even though no statistically significant differences were found between groups (Figure 1A). WT BMM $\varphi$ s treated with LPS also exhibited arginase activity and were absent in MyD88-/- mice. iNOS activity was monitored by measuring nitrite concentrations in the ВMM $\varphi$ supernatant fluids using the Greiss reagent. The results show that WT BMM $\varphi$ s (with or without IL-4 stimulation) produced nitrite when stimulated with LPS alone and with IFN- $\gamma$. A synergistic effect was observed on the iNOS activity with further upregulation when treated with both LPS and IFN- $\gamma$ compared with LPS or IFN- $\gamma$ treatment alone (Figure 1B). MyD88-/- BMM $\varphi$ showed similar trend with WT BMM $\varphi$ on NO production. However, almost no NO was detected upon stimulation with LPS alone compared with WT BMMps. Moreover, NO could be produced via pretreatment with IL-4 followed by stimulation with LPS alone. Treatment with IFN- $\gamma$ alone had no effect on NO production (in both WT and MyD88-/- BMM $\varphi$ ) even with IL-4 treatment (Figure 1B).

\section{MyD88-deficiency of has no effect on arginase-1, RELM $\alpha$, and $\mathrm{Ym} 1$ expression in BMM $\varphi$ s}

To ascertain further the phenotype of the AAM $\varphi$ s elicited by the F. hepatica infection, the gene expression of $\mathrm{AAM} \varphi$ markers arginase-1, RELM $\alpha$, and $\mathrm{Ym} 1$ in $\operatorname{BMM} \varphi$ were measured via real-time reverse transcriptase polymerase chain reaction (RT-PCR). The results show no deficiency in AAM $\varphi$ generation in the MyD88-/- animals. Figure 2 shows that arginase-1 expression in MyD88-/- BMM $\varphi$ treated with IL-4 was lower than that of WT BMM $\varphi$, and no expression on both untreated WT and MyD88-/- BMM $\varphi$. The expression profiles of both RELM $\alpha$ and $\mathrm{Ym} 1$ in the BMM $\mathrm{Bs}$ show similar trends with higher levels on the MyD88-/BMM $\varphi$ treated with IL-4; however, no statistically significant differences were found (Figure 2).

The Th2 cytokine bias is not significantly altered in $F$. hepatica-infected mice in the absence of MyD88 in vitro and in vivo

Ascertaining any effects on the overall Th2 response in F. hepatica-infected mice is essential before determining the effect of MyD88 knockdown on macrophage activation in vivo. Consequently, the Th2 cytokines IL-4, IL-5, IL-10, and IL-13, together with IFN- $\gamma$, a marker of Th1 response, were monitored in the supernatant fluids of cultured splenocytes treated with media, anti-CD3, or FhAg (Figures 3A-3E). The results showed that all Th2 cytokines were elevated on FhAg stimulation in the infected WT mice and were further increased in the MyD88-/- infected mice, although no statistically significant difference was found between the WT and MyD88-/- infected mice. In contrast, the Th1 response, as measured with IFN- $\gamma$ decreased significantly upon 

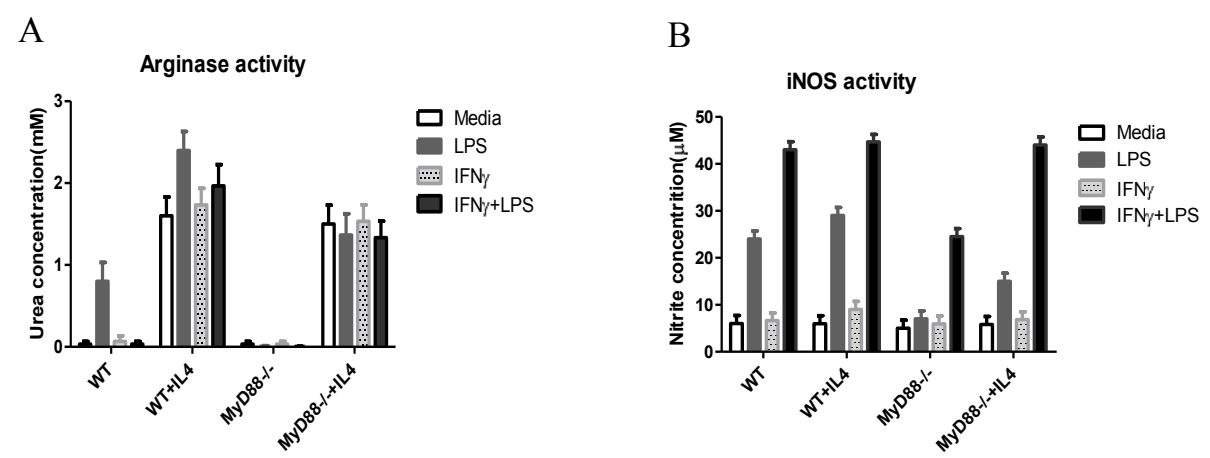

Figure 1 The absence of MyD88 has no effect on the AAM $\varphi$ s derived from bone marrow in vitro. The BMM $\varphi$ were treated with or without IL-4 followed by the stimulation with LPS and IFN- $\gamma$ together or separately for 12-24 h. (A). The urea concentration represents the arginase activity after the stimulation. (B). The nitrite concentration is shown as a measure of iNOS activity produced by the BMM were tested per group. Results are compiled from three independent experiments.

stimulation with FhAg or anti-CD3 but not media in the infected MyD88-/- mice compared with the WT infected mice (Figure 3E). Meanwhile, the thioglycolateinjected WT and MyD88-/- mice exhibited low levels of both Th1 and Th2 compared with their infected counterparts. The local cytokine production in the PEC supernatant fluid (Figures 4A-4E) was also measured. Significantly higher IL-4 levels were observed in the MyD88-/- infected mice compared with both the WT and the WT-infected mice (Figure. 4 A). Similar trends were seen in cytokine IL-5 and IL-13 (Figures 4B and 4C). However, no statistically significant difference in IL-10 production was found between the WT and MyD88-/- mice in both the thio and infection treatments. In contrast, the IFN- $\gamma$ in the both MyD88-/- thio and the MyD88-/- infected mice significantly decreased compared with that in THE $F$. hepatica-infected WT mice. Overall, these results show that the Th2 response is not impaired in F. hepatica-infected MyD88-/- mice both in vitro and vivo.
A

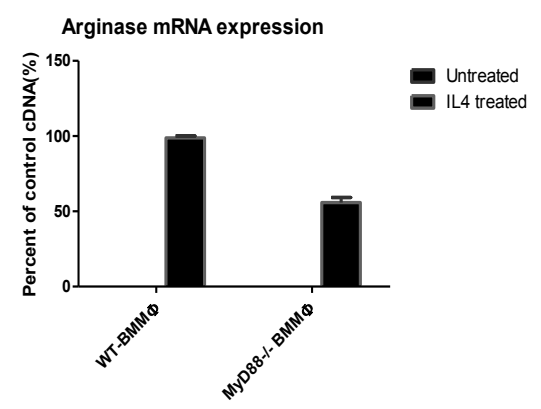

B

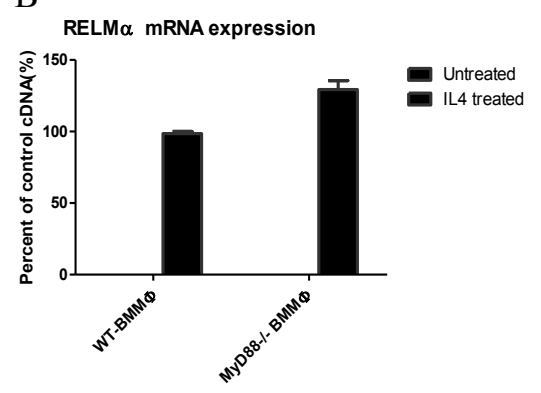

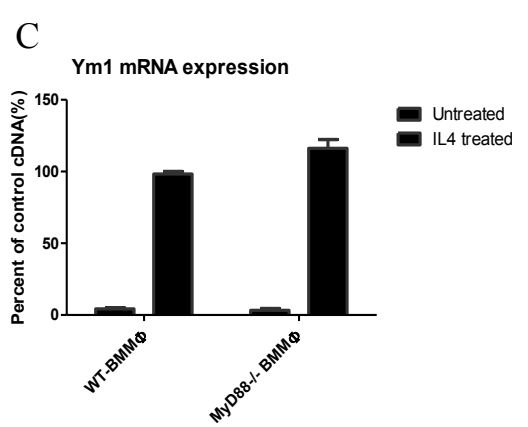

Figure 2 MyD88-deficiency did not impair arginase-1, RELM $\alpha$, and Ym1 expression in BMM $\mathbf{B}$ s. mRNA was extracted and real-time RT-PCR for arginase-1, RELM $\alpha$, and Ym1 expression was carried out to examine AAM $\varphi$ generation. The black bars represent the mRNA expression in mice treated with IL-4. The mRNA expression is shown as a percent of the positive control sample and $\beta$-actin was used to normalize the experiments. Results are compiled from three independent experiments. 


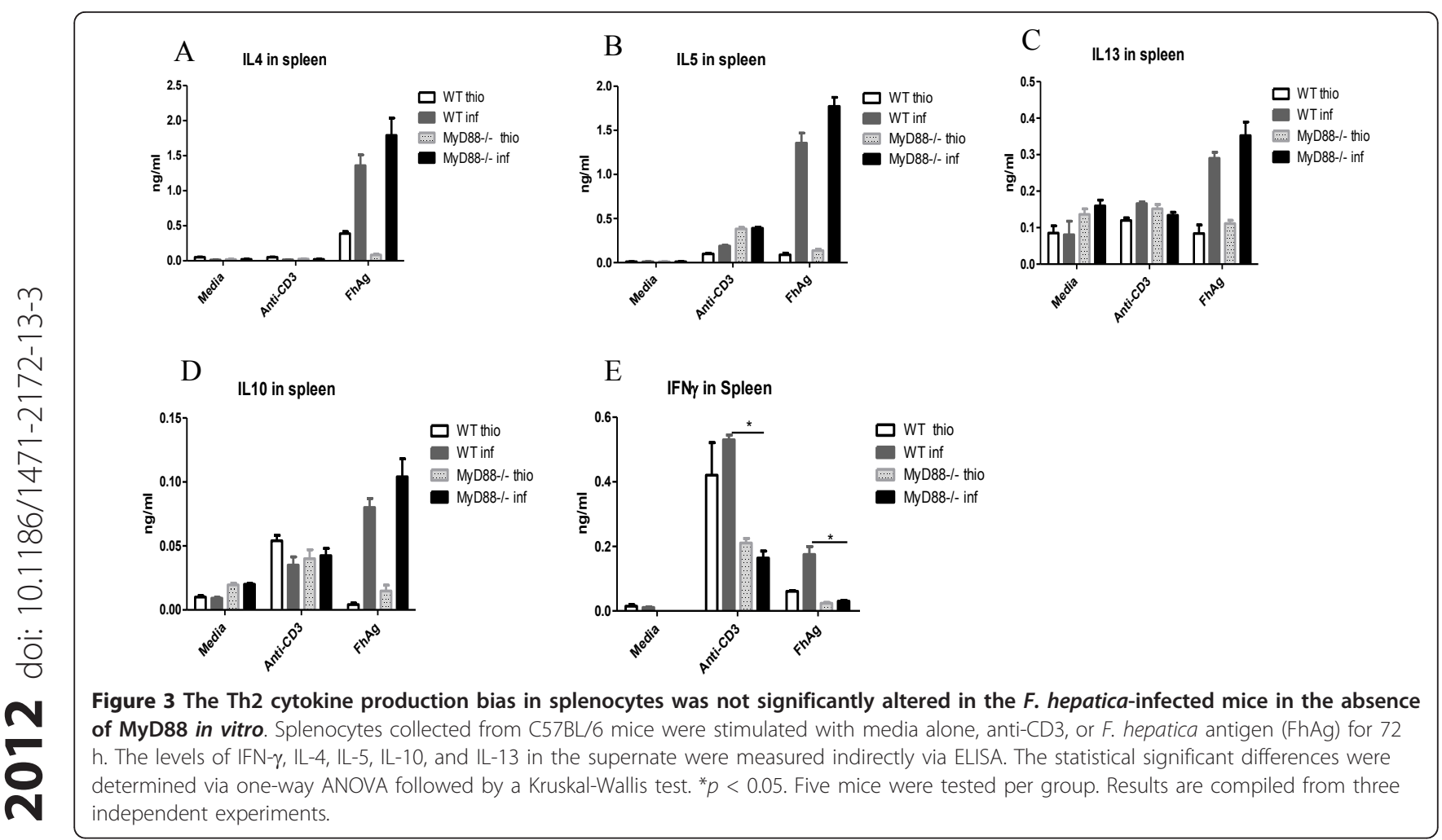

A
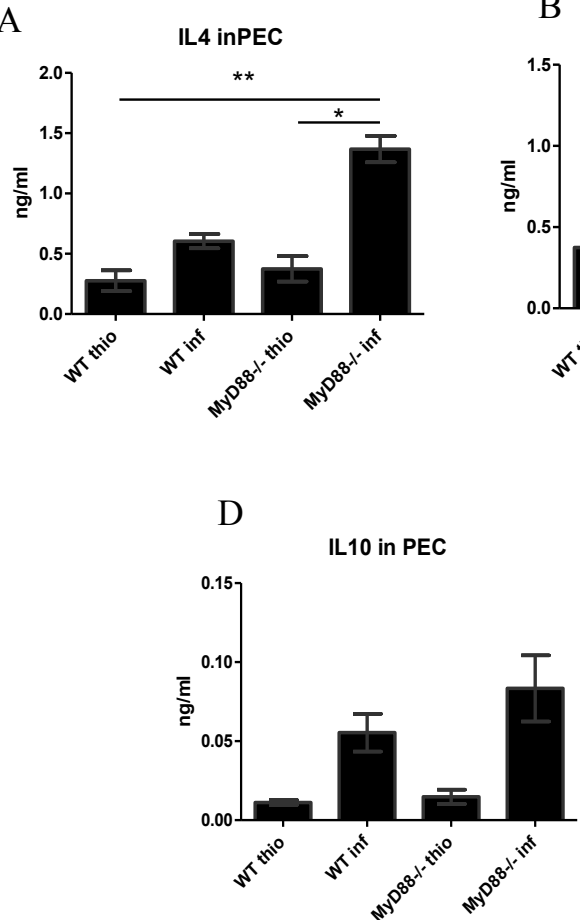
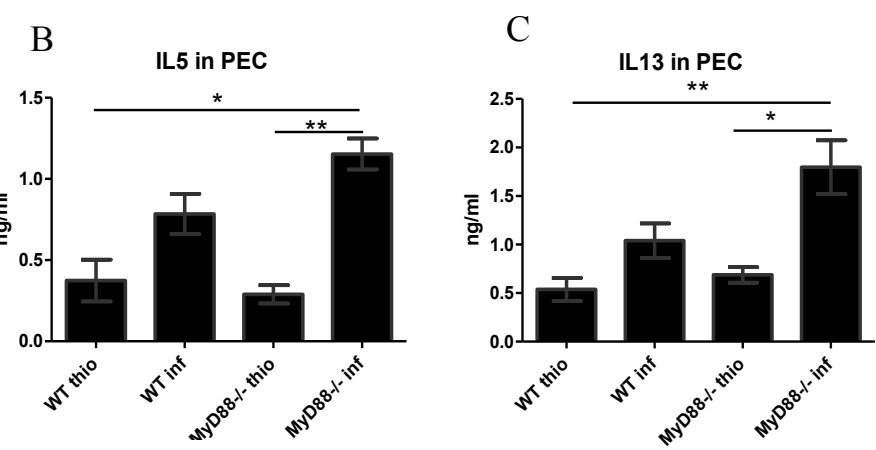

E

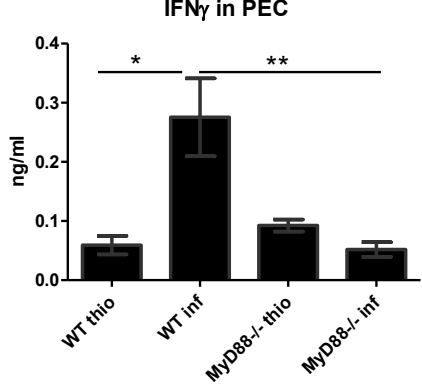

Figure 4 The Th2 cytokine production bias in the pleural cavity lavage was not significantly altered in the MyD88-deficient $F$. hepatica-infected mice. Peritoneal exudate cells (PEC) were collected from the C57BL/6 mice and were treated with media alone, anti-CD3, or F. hepatica antigen (FhAg) for $72 \mathrm{~h}$. The levels of IFN- $\gamma, \mathrm{IL}-4, \mathrm{IL}-5, \mathrm{IL}-10$, and IL-13 in the supernate were measured indirectly via ELISA. Statistical significances were determined via one-way ANOVA followed by a Kruskal-Wallis test. ${ }^{*} p<0.05$ and ${ }^{* *} p<0.01$. Five mice were tested per group. Results are compiled from three independent experiments. 


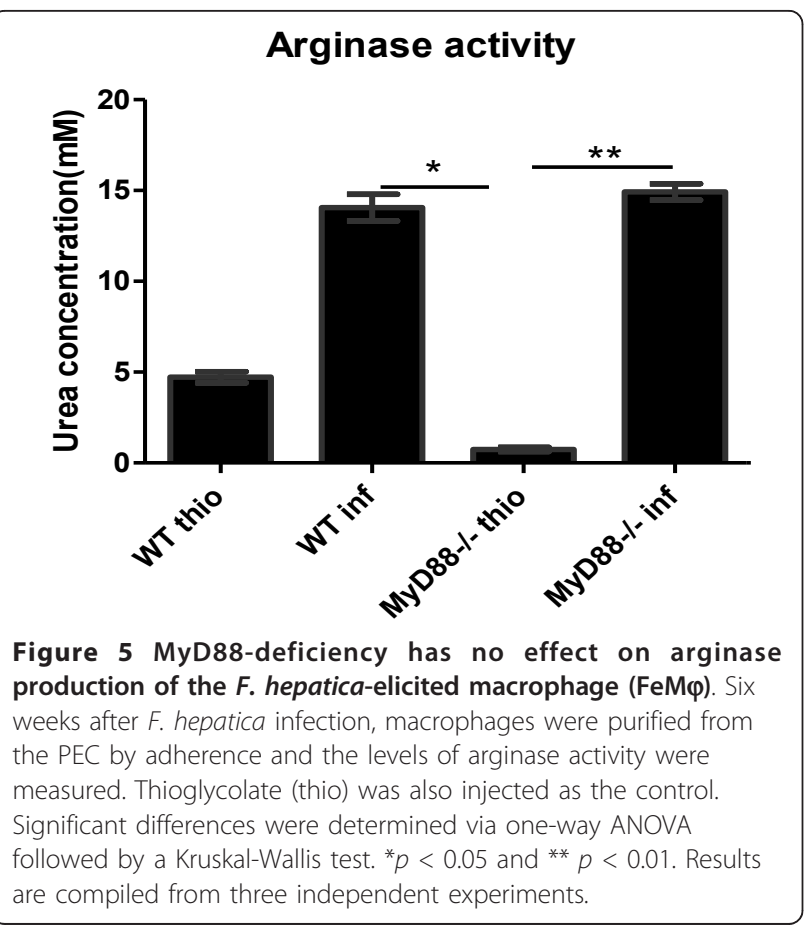

MyD88-deficiency did not affect the arginase production of the $F$. hepatica-elicited macrophages in PECs

To determine whether MyD88-deficiency affects production in macrophages recruited in PEC, the arginase activity levels were measured using the purified macrophages from the PEC (Figure 5). As shown, macrophages from $F$. hepatica-infected mice produced more arginase than macrophages from the mice treated with thioglycolate, and the MyD88-/- and WT infected mice produced significantly higher arginase than the MyD88-/- thio mice, although no difference was seen between the WT thio and the WT infected mice. In addition, no significant difference in arginase levels was observed between the WT and MyD88-/- infected mice.

The absence of MyD88 had no effect on RELM $\alpha$ and Ym1 production by cells in the peritoneal cavity after $F$. hepatica infection

We investigated whether the absence of MyD88 impairs RELM $\alpha$ and Ym1 expression in peritoneal lavage fluid using western blot analysis (Figures 6A and 6B) and real-time RT-PCR (Figure 7). As shown in the figure, although both the RELM $\alpha$ and Ym1 protein signals were detected in the WT and the MyD88-/- infected mice, no significant difference was found between these two groups. To determine whether the mRNA expression levels correlates with protein production, total RNA was extracted from purified macrophages in the peritoneal cavity and real-time RT-PCR was performed to detect RELM $\alpha$, Ym1, and arginase 1 mRNA expression (Figures 7A and 7B). Although WT and MyD88-/infected mice produced detectable RELM $\alpha$ and $\mathrm{Ym} 1$, they could not be detected in the WT and MyD88-/thio mice. No statistically significant difference in RELM $\alpha$ and Ym1 mRNA expression was observed between the WT and the MyD88-/- infected mice, which is consistent with the protein profiles of RELM $\alpha$ and Ym1 above.

\section{Discussion}

The data demonstrates that macrophages from a chronic infection, which consequently produce Th2 type cytokines at the stage wherein young $F$. hepatica penetrates the liver capsule and migrates through the liver tissue, do not require TLR signaling for AAM $\Phi$ induction.
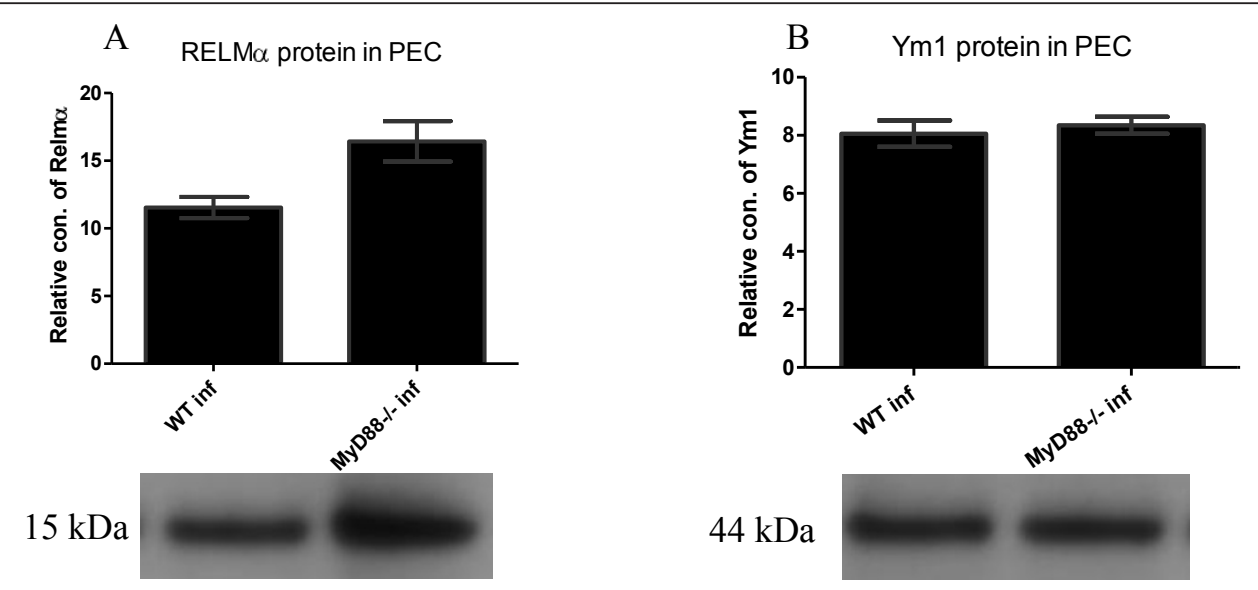

Figure 6 The Absence of MyD88 had no effect on the production of RELM $\alpha$ and Ym1 proteins by cells in the peritoneal cavity after F. hepatica infection. Six weeks after F. hepatica infection of C57BL/6 mice, peritoneal cavity lavages were performed and western blots for RELM $\alpha$ (A) and $Y m_{1}$ (B) were carried out on the lavage fluid. Image software was used to measure the relative concentrations of proteins on the blots. 

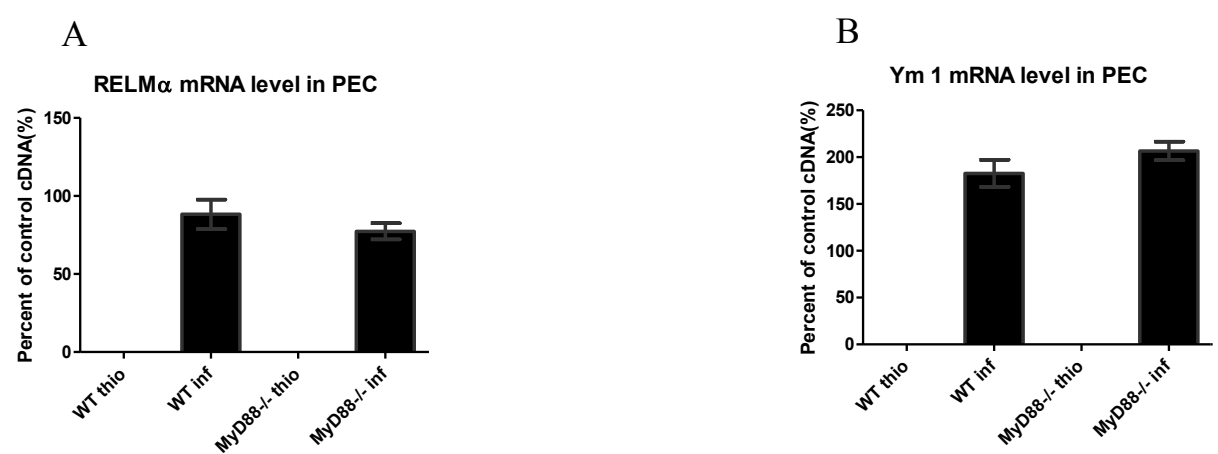

Figure 7 The lack of MyD88 has no effect on $\mathrm{Ym} 1$ and RELM $\alpha$ mRNA expression of macrophages from the peritoneal cavity. Six weeks after F. hepatica infection of C57BL/6 mice, the peritoneal cavity lavages were collected and macrophages were purified. RNA extraction and realtime RT-PCR were used for detection of RELM $\alpha$ (A) and Ym1 (B). mRNA expression is shown as a percent of the positive control sample and $\beta$ actin was used to normalize the experiments.

Like many other helminths, to establish successful chronic infections, F. hepatica induces Th2 responses characterized by increased IL-4, IL-5, and IL-13, activation and expansion of eosinophils, $\mathrm{CD} 4^{+}$cells, basophils, and mast cells [8-10,13,34-39]. Simultaneously, helminths release excretory-secretory proteins (ESP) to prevent dendritic cells and macrophages from acting on TLR2 Th1-stimulating ligands such as LPS and CpG during infections [40-42]. For example, cathepsin L1 cysteine protease released by $F$. hepatica suppresses the macrophage TLR recognition of LPS [43]. However, different infective stages may develop diverse immune responses. For instance, cytotoxic natural killer (CNK) cells dominate in the peritoneal fluid of $F$. hepaticainfected rats as early as 2 days post infection (p. i.). However, the cells decreased 4 days p.i. [44]. Therefore, the experimental set-up depends on the response outcomes needed. According to the life cycle of $F$. hepatica, the juvenile flukes penetrate the liver capsule and migrate through the liver tissue at 6 to 7 weeks before entering the bile ducts. This stage is rigorous for the host because of the violent penetration and migration of flukes. In addition, most activity detections of macrophages focus on the early stage of $F$. hepatica infection $[14,45,46]$; thus, little is known about the ААМФ at 6 weeks post $F$. hepatica infection, which is the reason why the AAM $\Phi$ phenotype in MyD88 deficient mice at this stage needs to be addressed.

The data demonstrates that the absence of MyD88 does not impair the Th2 response in F. hepaticainfected mice compared with the infected WT mice when the splenocytes in vitro were stimulated with FhAg. Furthermore, a non-statistically significant increase toward the Th2 response was also found in between. Moreover, the in vivo experiments also show that IL-4, IL-5, and IL-13 on MyD88-/- infected mice were significantly higher compared with the WT and
WT-infected mice. In contrast, the IFN- $\gamma$ in both the MyD88-/- thio and the MyD88-/- infected mice were significantly decreased compared with that in F. hepatica-infected WT mice, which indicates that a Th2dominant response was induced in vivo. This is consistent with the previous studies that provide evidence of elevated Th2 responses when MyD88-deficient mice were infected with Leishmania major [30,47], Chlamydia muridarum [48], or Schistosoma mansoni $[49,50]$. Similarly, MyD88 -/- mice infected with the gastrointestinal nematode Trichuris muris exhibited high resistance to infection and displayed an increase in IL-4 and IL-13 in cultured mesenteric lymph node cells with stimulation of T. muris specific antigen in vitro [51] compared with their WT counterparts. However, this was argued to be associated with powerful Th1 stimuli via a MyD88-dependent pathway because of the presence of commensal bacteria, which indicates the Th2 response to nematodes might be impaired because of increased Th1 response [52]. This is supported by experiments on S. mansoni showing that the absence of MyD88 supports Th2 responses [50]. However, in the present study, $F$. hepatica infection was not yet reported to carry any bacteria, which may mount a Th1 response. Therefore, no significant augmentation was seen in the MyD88 deficient mice. However, the Th2 response was clearly induced in the WT mice and mice lacking MyD88 with $F$. hepatica infection. As demonstrated by previous studies, Th2 response induced by helminth infections contribute to AАM $\Phi$ production (reviewed in [53]), F. hepatica infection may promote ААМФ. This is supported by the fact that AAM $\Phi$ could be produced by FhAg combined with IL-4 and stimulation with FhAg together with LPS (as a stimulus for TLR4 activity) or purified protein derivative from Mycobacterium bovis (PPD-B, as a stimulus for TLR2 activity) in WT mice resulted in reduced $\mathrm{NO}$ or IFN- $\gamma$ production, 
respectively [54]. Also, the thioredoxin peroxidase (TPX) secreted by $F$. hepatica induced the ААM $\Phi$ on cell lines in vitro $[14,15]$. Along with the present study, an implication that MyD88 deficiency is dispensable to the $\operatorname{AAM} \varphi$ may be reached.

The present study implies that MyD88 is not required for Th2 response and AAM $\varphi$ activation. In WT BMM $\varphi$, arginase production increased on treatment with LPS, which signals through the TLR4 pathway, which is consistent with the reports that LPS helps induce the production of both arginase isoforms (arginase-1 and arginase-2) [32,55]. Further, the arginase activity in MyD88-/- BMM $\varphi$, treated with the media, LPS, IFN- $\gamma$, or both was almost absent, indicating that this activity is MyD88-independent. In both the WT and MyD88-/BMM $\varphi$, arginase mRNA increased upon treatment with IL-4, which is in agreement with the reports that arginase could be induced when stimulated with IL-4 [56] Similar trends were seen in the production of RELM $\alpha$ and $\mathrm{Ym} 1 \mathrm{mRNA}$ in WT and MyD88-/- BMM $\varphi$ in response to IL-4. These findings offering further evidence that AAM $\varphi$ is induced in MyD88 deficient mice. On the other hand, NO was produced synergistically by MyD88-/- BMM $\varphi$ when stimulated with both LPS and IFN- $\gamma$ together, whereas it was produced by WT BMM $\varphi$ when treated with LPS alone. The NO produced by macrophages is essential to the suppression of host cytotoxicity and its production may be MyD88-dependent or -independent. In the present study, LPS signals through the TLR4 via the IRF-3 pathway during MyD88-deficiency, resulting in an increase in IFN $\beta$ instead of iNOS. IFN $\beta$ then induces IRF-1 production, which leads to the production of NO with the help of IFN- $\gamma$. This was supported by Koide et al. [57], who showed that the LPS-dependent increase in iNOS mRNA expression induced by IFN- $\gamma$ is attributed to the IRF-1 upregulation induced by LPS. Moreover, iNOS cannot be induced by IFN- $\gamma$ alone because of the lack of IRF-1 in the absence of MyD88. However, this speculation was not yet investigated.

Considering no significant difference was found in the Th2 cytokine profiles between the WT and MyD88-deficient mice, the lack of MyD88 may have affected the production of macrophages. However, the arginase activity in the macrophages from the PEC were at approximately the same level in the WT and MyD88-/AAM $\varphi$ s (Figure 5) despite both being significantly higher than those in MyD88 -/- thio AAM $\varphi$ s. RELM $\alpha$ and $\mathrm{Ym} 1$ Protein expression in the peritoneal cavity were not impaired with the MyD88-deficiency (Figure 6) and the mRNA expression of both genes (Figure 7) retained the same profiles as the protein expression, respectively. However, some effects on the response to thioglycolate treatment of the MyD88-deficient mice were observed, which indicates the partial role of TLR stimulus in thioglycolate-induced macrophage phenotype. These findings may be related to the mixture of TLR ligands in thioglycolate, which might have been ignored when the actual function of thioglycolate in macrophage activation was analyzed. All of these findings support that MyD88 is not required for macrophage activation during $F$. hepatica infection.

\section{Conclusion}

In summary, MyD88 is not required for AAM $\varphi$ induction in vitro and in vivo. In addition, the Th2 cytokine profile remained intact in the MyD88-deficient mice infected with the F. hepatica 6 weeks post infection.

\section{Methods}

\section{Mice and infection}

All animal experiments were carried out in the Animal Care and Ethics Center. Female C57BL/6 mice (6-7 weeks old) were purchased from Slaccas Experimental Animal Company. MyD88-/- mice were bred at the experimental animal center and were in the 5th and 6th generation of backcross to C57BL/6 mice. All mice were raised with free access to tap water and standard rodent diet under a pathogen-free- environment. All mice were maintained based on the Institutional and National Institutes of Health guidelines.

The wild type (WT) and Myd88-/- mice with C57BL/6 background were infected orally with 45 Faciola hepatica metacercariae. The metacercariae were collected from miracidia-infected Galba truncatula snails. All mice were euthanized 10 weeks post infection and the peritoneal exudate cells (PEC) were harvested by lavaging the peritoneal cavity with $10 \mathrm{~mL}$ ice-cold Dulbecco's modified Eagle's medium (DMEM) (Gibco) for mRNA extraction, western blotting, and/or cytokine analysis. The spleen was used for cell culture, which was used for the detection of cytokines in vitro. Then, 0.6 $\mathrm{mL}$ of $5 \%$ thioglycolate medium (Becton Dickinson) per mice were injected as the non-Th2 polarized inflammation control.

\section{Activation of $\mathrm{BMM} \varphi$}

The BMM $\varphi$ s from the C57BL/6 mice were harvested from the bone marrow in the femur and tibia. Macrophage differentiation was carried out based on previous literature [58]. Briefly, erythrocytes were treated with 3 $\mathrm{mL}$ red blood cell lysis buffer (Sigma-Aldrich) for $5 \mathrm{~min}$. The cells were cultured at $5 \times 10^{6}$ cells per plate in DMEM with $20 \%$ Fetal Calf Serum (FCS) (GIBCO), 20\% L929 supernatant, $2 \mathrm{mM}$ L-glutamine, $0.25 \mathrm{U} / \mathrm{mL}$ penicillin, and $100 \mu \mathrm{g} / \mathrm{mL}$ streptomycin. The medium was replaced to obtain pure macrophages at six days post culture. The collected BMM $\varphi$ were stored in fresh Petri 
dishes for 20-24 h with or without IL-4 (25 ng/mL; BD Pharmingen) followed by treatment with LPS (100 ng/ $\mathrm{mL}$; Escherichia coli 0111:B4, Sigma-Aldrich) and IFN- $\gamma$ (10 U/mL; BD Pharmingen) for 20-24 h together or separately.

\section{Measurement of Nitric Oxide (NO)}

NO was detected via nitrite accumulation in the macrophage culture media using Greiss Reagent (SigmaAldrich). Briefly, $100 \mu \mathrm{L}$ of the supernatant fluid and $100 \mu \mathrm{L}$ of $5.8 \%$ phosphoric acid (Sigma-Aldrich), 1\% sulfanilamide (Sigma-Aldrich), 0.1\% N-(1-naphthyl) ethylenediamine dihydrochloride (Sigma-Aldrich) were briefly mixed. The absorbance was read at $540 \mathrm{~nm}$ on a microplate reader. The NO concentration was determined based on a standard sodium nitrite solution curve.

\section{Determination of arginase activity}

Arginase activity was measured according to the previous literature [23]. Briefly, $1 \times 10^{5}$ macrophage cells were treated with $100 \mu \mathrm{L}$ 0.1\% Triton X-100 (SigmaAldrich) and $100 \mu \mathrm{L}$ of $25 \mathrm{mM}$ Tris-HCL (SigmaAldrich). After a 30-min shaking incubation, $20 \mu \mathrm{L}$ of $10 \mathrm{mM} \mathrm{MnCl} \mathrm{Mn}_{2}$ (Sigma-Aldrich) was added. Then, the cells were heated at $56^{\circ} \mathrm{C}$ for $10 \mathrm{~min}$ to activate the enzyme and $100 \mu \mathrm{L}$ of this lysate with $100 \mu \mathrm{L}$ of $0.5 \mathrm{M}$ L-arginine ( $\mathrm{pH} 9.7$, Sigma-Aldrich) was incubated at $37^{\circ}$ $\mathrm{C}$ for $60 \mathrm{~min}$ to examine the L-arginine hydrolysis. The reaction was stopped with addition of $800 \mu \mathrm{L}$ of $\mathrm{H}_{2} \mathrm{SO}_{4}$ $(96 \%) / \mathrm{H}_{3} \mathrm{PO}_{4}(85 \%) / \mathrm{H}_{2} \mathrm{O}(1 / 3 / 7, \mathrm{v} / \mathrm{v} / \mathrm{v})$, and $40 \mu \mathrm{L}$ of $9 \%$ isonitroso-propiophenone (Sigma-Aldrich). The cells were then heated at $99^{\circ} \mathrm{C}$ for $30 \mathrm{~min}$. The plates were read at $540 \mathrm{~nm}$ on a microplate reader. Arginase enzyme activity was determined based on a standard urea solution curve.

\section{Preparation of $F$. hepatica antigens}

Fresh $F$. hepatica adults from infected mice were washed with phosphate-buffered saline (PBS, pH 7.3) solution. The worms were homogenized with $10 \mathrm{mM}$ Tris- $\mathrm{HCl}(\mathrm{pH} 7.2), 150 \mathrm{mM}$ EDTA at $4^{\circ} \mathrm{C}$ and sonicated on ice for $5 \mathrm{~min}$. The homogenates were centrifuged at $12,000 \times \mathrm{g}$ at $4^{\circ} \mathrm{C}$ for $1 \mathrm{~h}$. The supernatant fluids were harvested as F. hepatica extracted antigen (FhAg). The protein concentrations were detected using a BCA protein assay kit (Invitrogen, UK).

\section{Cell culture and stimulation}

Splenic cells and PECs were cultured in vitro. The spleens were crushed and the cells were centrifuged at $1100 \times \mathrm{g}$ for $5 \mathrm{~min}$, and then resuspended at $5 \times 10^{6} \%$ $\mathrm{mL}$. The supernatant fluid was abandoned after the addition of $3 \mathrm{~mL}$ of RBC Lysis Buffer (Sigma). The cells were centrifuged at $1100 \times \mathrm{g}$ for $5 \mathrm{~min}$ followed by a final re-suspension at $10^{7} / \mathrm{mL}$ with the addition of 10 $\mathrm{mL}$ of RPMI 1640. The cells were dispensed at $5 \times 10^{5}$ cells per well. A final volume of $200 \mu \mathrm{L}$ of splenic cells in triplicate were cultured with FhAg $(10 \mu \mathrm{g} / \mathrm{mL}), \mathrm{RPMI}$ 1640 media and anti-CD3 $(1 \mu \mathrm{g} / \mathrm{mL})$ at $37^{\circ} \mathrm{C}$ in $5 \% \mathrm{CO}_{2}$ for $48 \mathrm{~h}$, followed by the addition of $10 \%$ of total volume Alamar Blue (Invitrogen, UK) for another $24 \mathrm{~h}$. The plates were read at $540 \mathrm{~nm}$ for cell proliferation and the supernatant fluids were harvested and kept at $-20^{\circ} \mathrm{C}$ for further cytokine analyses after centrifugation at $1100 \times \mathrm{g}$ for $2 \mathrm{~min}$. PEC culture and stimulation were performed similar to that for the splenocytes above.

\section{Cytokine determination}

IL-4, IL-5, IL-10, IL-13, and IFN- $\gamma$ in the spleen and PEC supernatant fluid were detected by sandwich ELISA. The plates were coated with carbonate-buffered capture antibodies at $50 \mu \mathrm{L} /$ well (the dilution factor was 1:500 for IL4, IFN- $\gamma$ and 1: 250 for IL-5, IL-10, and IL-13) and incubated overnight at $4{ }^{\circ} \mathrm{C}$. The plates were incubated in $4 \%$ BSA PBS $(200 \mu \mathrm{L} /$ well $)$ for $2 \mathrm{~h}$ at room temperature in the dark, followed by addition of $50 \mu \mathrm{L} /$ well 2 -fold diluted standard antibodies (top concentration: IL-4 at 8 $\mathrm{ng} / \mathrm{mL}$; IL-5, IL-10, and IL-13 at $10 \mathrm{ng} / \mathrm{mL}$; IFN- $\gamma$ at 50 $\mathrm{ng} / \mathrm{mL}$ diluted with $1 \%$ BSA PBS) in duplicate after washing. Then, $50 \mu \mathrm{L} /$ well of the spleen or PEC supernatant samples were then added and incubated overnight at $4^{\circ} \mathrm{C}$, followed by incubation in biotinylated antibodies (final dilution: IL-4, IL-5, IFN- $\gamma$ at $1 \mu \mathrm{g} / \mathrm{mL}$; IL-10 and IL-13 at $2 \mu \mathrm{g} / \mathrm{mL}$ in $1 \%$ BSA PBS) for $1 \mathrm{~h}$ at room temperature and AMDEX streptavidin-peroxidase (Sigma, France) at dilution 1: 6000 in 1\% BSA PBS for $30 \mathrm{~min}$. Finally, 50 $\mu \mathrm{L} /$ well of TMB (KPL) was added and reaction was stopped with the addition of $50 \mu \mathrm{L}$ of $1 \mathrm{mM} \mathrm{H}_{2} \mathrm{SO}_{4}$. The absorbance was read at $450 \mathrm{~nm}$.

\section{Relative quantification of genes}

The expression of arginase-1, RELM $\alpha$, and Ym-1 genes were quantified via real-time RT-PCR. Total RNA was extracted according to the manufacturer's instructions. Approximately $1 \mu \mathrm{g}$ of the total RNA was used to synthesize cDNA using MMLV reverse transcriptase (Stratagene). Then, the relative quantification of the genes was determined using a Light Cycler (Roche Molecular Biochemicals). A cDNA (FeM $\varphi$ )-positive control sample with five serial (1:4) dilutions was used as the standard curve in each reaction. $\beta$-Actin was used to normalize the expression of the test genes. A $10 \mu \mathrm{L}$ reaction containing $1 \mu \mathrm{L}$ cDNA, $4 \mathrm{mM} \mathrm{MgCl}_{2}, 0.3 \mathrm{mM}$ primers, and the Light Cycler-DNA SYBR Green I mix was carried out under the following conditions: denaturation at $95^{\circ} \mathrm{C}$ for $40 \mathrm{~s}$, annealing at $54^{\circ} \mathrm{C}$ for $10 \mathrm{~s}$, and elongation at $72^{\circ} \mathrm{C}$ for $15 \mathrm{~s}, 45-55$ cycles. The annealing 
Table 1 Primers used for real-time PCR analysis

\begin{tabular}{|c|c|c|c|}
\hline Gene & Forward & Reverse & $\begin{array}{l}\text { Annealing } \\
\text { Temp }\left({ }^{\circ} \mathrm{C}\right)\end{array}$ \\
\hline Arginase1 & GGTCCAGAAGAATGGAAGAGTCAG & CAGATATGCAGGGAGTCACC & 54 \\
\hline RELM $\alpha$ & GGTCCCAGTGCATATGGATGAGACCATAGA & CACCTCTTCACTCGAGGGACAGTTGGCAGC & 54 \\
\hline Ym1 & TCACAGGTCTGGCAATTCTTCTG & TTGTCCTTAGGAGGGCTTCCTCG. & 62 \\
\hline$\beta$-Actin & GAATCCTGTGGCATCCATGAAAC & TAAAACGCAGCTCAGTAACAGTCCG & 54 \\
\hline
\end{tabular}

temperature for $\mathrm{Ym} 1$ was set to $62^{\circ} \mathrm{C}$. The primers used for light cycler PCR analysis are listed in Table 1.

\section{Western blot analysis}

Up to $20 \mu \mathrm{L}$ of the peritoneal cavity lavage fluid was mixed with LDS sample loading buffer (NuPAGE) and heated to resolve by SDS-PAGE using 4\%-12\% NuPAGE gel. The proteins were transferred from the gel onto a cellulose nitrate membrane by electrophoresis at $30 \mathrm{~V}$ for $1 \mathrm{~h}$. Then, the membranes were incubated for $1 \mathrm{~h}$ in $5 \%$ skimmed milk in TBS and incubated with Anti-Ym1 (produced by immunization of the mice with recombinant protein, diluted in 5\% skimmed milk in TBS blocking buffer: 1/3000) and anti-RELM $\alpha$ (produced by immunization of the mice with recombinant protein, 1/ 500) antibodies separately after $1 \mathrm{~h}$ block, followed by incubation with goat anti-mouse IgG alkaline phosphatase conjugate (1:5000) for $8 \mathrm{~h}$. Then, it was incubated with the substrate (specify) Chemi Glow (luminol/ enhancer solution: stable peroxide buffer $=1: 1$ ) until the color developed. The reaction was ceased by absorption of the rest of substrates. The results were recorded using the Gel Image System (Bio-Rad). Image software was used to measure the relative concentrations of proteins on the blots.

\section{Statistical analysis}

One-way ANOVA was applied to evaluate the statistical differences between groups. The non-parametric KruskalWallis rank sum test along with Dunn's test was applied on all analyses. Differences with $P<0.05$ were considered significant. The values are presented as mean \pm SE unless otherwise stated. All graphs were made using PRISM software (version 5.0, GraphPad Software, Berkeley, CA).

\section{List of Abbreviations}

Abbreviations: AAMФ: alternatively activated macrophages; CAMФ: classically activated macrophages; MyD88: myeloid differentiation factor 88; TLRs: Tolllike receptors; PRRs: pattern recognition receptors; PAMPs: pathogenassociated molecular patterns; LPS: lipopolysaccharide; IFN- $\gamma$ : interferon- $\gamma$; PEC: peritoneal exudate cells; FhAg: F. hepatica extracted antigen; ELISA: enzyme-linked immunosorbent assay; WT: wild type; MyD88-/-: MyD88 knockout.

\section{Acknowledgements}

This work was supported by China Scholarship Council (CSC) and the Fundamental Research Funds for the Central Universities (XDJK2009B001)
We are grateful to Nick Green for excellent technical assistance and Professor Wang hong for reading of the manuscript.

\begin{abstract}
Author details
'Laboratory of Infection \& Immunology Research, College of Animal Science \& Technology, Southwest University, Chongqing, China. ${ }^{2}$ Parasitology department, College of Animal Science \& Technology, Guangxi University, Nanning, China. ${ }^{3}$ ENVA, UMR BIPAR, Ecopham, Ecole Nationale Vétérinaire d'Alfort, Maisons-Alfort, France.
\end{abstract}

\section{Authors' contributions}

LHL conceived, designed and coordinated the study, performed the experimental work, data collection and drafted the manuscript. WDY participated in the design of the study, analysis of assay and data collection. WHJ collected parasite materials and performed biological assay, also developed methodologies for the antibody production of RELMa and Ym1. NK developed methodologies for biochemical assay and Western blotting optimization, also provided crucial reagents and advice. All authors read and approved the manuscript.

\section{Competing interests}

The authors declare that they have no competing interests.

Received: 21 September 2011 Accepted: 11 November 2011 Published: 11 November 2011

\section{References}

1. Edwards JP, Zhang X, Frauwirth KA, Mosser DM: Biochemical and functional characterization of three activated macrophage populations. $J$ Leukoc Biol 2006, 80:1298-1307.

2. Mosser DM, Edwards JP: Exploring the full spectrum of macrophage activation. Nat Rev Immunol 2008, 8:958-969.

3. Stein M, Keshav S, Harris N, Gordon S: Interleukin 4 potently enhances murine macrophage mannose receptor activity: a marker of alternative immunologic macrophage activation. J Exp Med 1992, 176:287-292.

4. Kawashima R, Kawamura Y I, Kato R, Mizutani N, Toyama-Sorimachi N, Dohi T: IL-13 receptor alpha2 promotes epithelial cell regeneration from radiation-induced small intestinal injury in mice. Gastroenterology 2006, 131:130-141.

5. Raes G, Beschin A, Ghassabeh GH, de Baetselier P: Alternatively activated macrophages in protozoan infections. Current Opinion in Immunology 2007, 19(4):454-459.

6. Gordon S: Alternative activation of macrophages. Nature Reviews Immunology 2003, 3(1):23-35

7. Welch JS, Escoubet-Lozach L, Sykes DB, Liddiard K, Greaves DR, Glass CK $\mathrm{TH} 2$ cytokines and allergic challenge induce $\mathrm{Ym} 1$ expression in macrophagesby a STAT6-dependent mechanism. Journal of Biological Chemistry 2002, 277(45):42821-42829.

8. Morimoto M, Whitmire J, Xiao S, Anthony RM, Mirakami H, Star RA, Urban JF Jr, Gause WC: Peripheral CD4 T cells rapidly accumulate at the host: parasite interface during an inflammatory Th2 memory response. $J$ Immunol 2004, 172:2424-2430.

9. Herbert DR, Holscher C, Mohrs M, Arendse B, Schwegmann A, Radwanska M, Leeto M, Kirsch R, Hall P, Mossmann M, Claussen B, Forster I, Brombacher F: Alternative macrophage activation is essential for survival during schistosomiasis and downmodulates T helper 1 responses and immunopathology. Immunity 2004, 20:623-635.

10. Rodríguez-Sosa M, Satoskar AR, Caldero'n R, Gomez-Garcia L, Saavedra R, Bojalil $\mathrm{R}$, Terrazas LI: Chronic helminth infection induces alternatively activated macrophages expressing high levels of CCR5 with low 
interleukin-12 production and Th2-biasing ability. Infect Immun 2002, 70:3656-3664.

11. Nair MG, Cochrane DW, Allen JE: Macrophages in chronic type 2 inflammation have a novel phenotype characterized by the abundant expression of $\mathrm{Ym} 1$ and Fizz1 that can be partly replicated in vitro. Immunol Lett 2003, 85:173-180.

12. Lee CG, Hartl D, Lee GR, Koller B, Matsuura H, Da Silva CA, Sohn MH, Cohn L, Homer RJ, Kozhich AA, Humbles A, Kearley J, Coyle A, Chupp G, Reed J, Flavell RA, Elias JA: Role of breast regression protein 39 (BRP-39)/ chitinase 3-like-1 in Th2 and IL-13-induced tissue responses and apoptosis. Journal of Experimental Medicine 2009, 206(5):1149-1166.

13. Anthony RM, Urban JF Jr, Alem F, Hamed HA, Rozo CT, Boucher JL, Van Rooijen N, Gause WC: Memory TH2 cells induce alternatively activated macrophages to mediate protection against nematode parasites. Nature Med 2006, 12:955-960.

14. Donnelly S, O'Neill SM, Sekiya M, Mulcahy G, Dalton JP: Thioredoxin peroxidase secreted by Fasciola hepatica induces the alternative activation of macrophages. Infect Immun 2005, 73:166-173.

15. Flynn RJ, Irwin JA, Olivier M, Sekiya M, Dalton JP, Mulcahy G: Alternative activation of ruminant macrophages by Fasciola hepatica. Vet Immunol Immunopathol 2007, 120:31-40

16. Munder M, Eichmann K, Moran JM, Centeno F, Soler G, Modolell M: Th1/ Th2-regulated expression of arginase isoforms in murine macrophages and dendritic cells. J Immunol 1999, 163:3771-3777.

17. Raes G, Noel W, Beschin A, Brys L, de Baetselier P, Hassanzadeh GH: FIZZ1 and $\mathrm{Ym}$ as tools to discriminate between differentially activated macrophages. Dev Immunol 2002, 9:151-159.

18. Raes $G$, Van den Bergh R, De Baetselier P, Ghassabeh GH, Scotton C, Locati M, Mantovani A, Sozzani S: Arginase-1 and Ym1 Are Markers for Murine, but Not Human, Alternatively Activated Myeloid Cells. The Journal of Immunology 2005, 174:6561-6562.

19. Nair MG, Guild KJ, Artis D: Novel effector molecules in type 2 inflammation: lessons drawn from helminth infection and allergy. $J$ Immunol 2006, 177:1393-1399.

20. Sutherland TE, Allen JE: Chitinases and chitinase-like proteins: potential therapeutic targets for the treatment of T-helper type 2 allergies. Clinical and Experimental Allergy 2009, 39(7):943-955.

21. Holcomb IN, Kabakoff RC, Chan B, Baker TW, Gurney A, Henzel W, Nelson C, Lowman HB, Wright BD, Skelton NJ, Frantz GD, Tumas DB, Peale FV Jr, Shelton DL, Hébert CC: FIZZ1, a novel cysteine-rich secreted protein associated with pulmonary inflammation, defines a new gene family. The EMBO Journal 2000, 19(15):4046-4055.

22. Steppan CM, Brown EJ, Wright CM, Bhat S, Banerjee RR, Dai CY, Enders GH, Silberg DG, Wen X, Wu GD, Lazar MA: A family of tissue-specific resistinlike molecules. Proc Natl Acad Sci USA 2001, 98(2):502-506.

23. Munder M, Eichmann K, Modolell M: Alternative metabolic states in murine macrophages reflected by the nitric oxide synthase/arginase balance: competitive regulation by CD4+ T cells correlates with Th1/Th2 phenotype. J Immunol 1998, 160(11):5347-5354.

24. Bronte V, Serafini P, Mazzoni A, Segal DM, Zanovello P: L-arginine metabolism in myeloid cells controls T-lymphocyte functions. Trends in immunology 2003, 24(6):302-306.

25. Kawai T, Akira S: The roles of TLRs, RLRs and NLRs in pathogen recognition. Int Immunol 2009, 21:317-337.

26. Chao W: Toll-like receptor signaling: a critical modulator of cell survival and ischemic injury in the heart. Am J Physiol Heart Circ Physiol 2009, 296: $\mathrm{H} 1-\mathrm{H} 12$

27. Kawai T, Akira S: TLR signaling. Cell Death Differ 2006, 13:816-825.

28. Yamamoto M, Sato S, Hemmi H, Hoshino K, Kaisho T, Sanjo H, Takeuchi O, Sugiyama M, Okabe M, Takeda K, Akira S: Role of adaptor TRIF in the MyD88-independent toll-like receptor signaling pathway. Science 2003, 301:640-643.

29. Kaisho T, Hoshino K, Iwabe T, Takeuchi O, Yasui T, Akira S: Endotoxin can induce MyD88-deficient dendritic cells to support $T(h) 2$ cell differentiation. Int Immunol 2002, 14:695-700.

30. Muraille E, De Trez C, Brait M, De Baetselie P, Leo O, Carlier Y: Genetically resistant mice lacking MyD88-adapter protein display a high susceptibility to Leishmania major infection associated with a polarized Th2 response. J Immunol 2003, 170:4237-4241.
31. Eisenbarth SC, Piggott DA, Huleatt JW, Visintin I, Herrick CA, Bottomly K: Lipopolysaccharide-enhanced, toll-like receptor 4-dependent T helper cell type 2 responses to inhaled antigen. J Exp Med 2002, 196:1645-1651.

32. Louis CA, Mody V, Henry WL Jr, Reichner JS, Albina JE: Regulation of arginase isoforms I and II by IL-4 in cultured murine peritoneal macrophages. Am J Physiol 1999, 276:R237-242.

33. Mori M, Gotoh T: Regulation of nitric oxide production by arginine metabolic enzymes. Biochem Biophys Res Commun 2000, 275:715-719.

34. Gause WC, Urban JF, Stadecker MJ: The immune response to parasitic helminths: insights from murine models. Trends Immunol 2003, 24:269-277.

35. Cliffe $L J$, Grencis RK: The Trichuris muris system: a paradigm of resistance and susceptibility to intestinal nematode infection. Adv Parasitol 2004 57:255-307.

36. Mantovani A, Sica A, Locati M: Macrophage polarization comes of age. Immunity 2005, 23:344-346

37. Gupta R, Bajpai P, Tripathi LM, Srivastava VM, Jain SK, Misra-Bhattacharya S: Macrophages in the development of protective immunity against experimental Brugia malayi infection. Parasitology 2004, 129:311-323.

38. Taylor MD, Harris A, Nair MG, Maizels RM, Allen JE: F4/80+ alternatively activated macrophages control $\mathrm{CD} 4+\mathrm{T}$ cell hyporesponsiveness at sites peripheral to filarial infection. J Immunol 2006, 176:6918-6927.

39. Reece JJ, Siracusa MC, Scott AL: Innate immune responses to lung-stage helminth infection induce alternatively activated alveolar macrophages Infect Immun 2006, 74:4970-4981.

40. Carvalho L, Sun J, Kane C, Marshall F, Krawczyk C, Pearce EJ: Review series on helminths, immune modulation and the hygiene hypothesis: mechanisms underlying helminth modulation of dendritic cell function. Immunol 2009, 126:28-34.

41. Siracusa MC, Urban JF, Scott AL: Dynamics of lung macrophage activation in response to helminth infection. J Leukoc Biol 2008, 84:1422-1433.

42. Goodridge HS, Marshall FA, Else KJ, Houston KM, Egan C, Al-Riyami L, Liew FY, Harnett W, Harnett MM: Immunomodulation via novel use of TLR4 by the filarial nematode phosphorylcholine-containing secreted product, ES-62. J Immunol 2005, 174:284-293.

43. Donnelly S, O'Neill SM, Stack CM, Robinson MW, Turnbull L, Whitchurch C Dalton JP: Helminth cysteine proteases inhibit TRIF-dependent activation of macrophages via degradation of TLR3. The Journal of Biological Chemistry 2010, 285(5):3383-3392.

44. Jedlina L, Kozak-Ljunggren M, Wedrychowicz H: In vivo studies of the early, peritoneal, cellular and free radical response in rats infected with Fasciola hepatica by flow cytometric analysis. Exp Parasitol 2011, 128(3):291-297.

45. Clery D, Torgerson P, Mulcahy G: Immune responses of chronically infected adult cattle to Fasciola hepatica. Vet Parasitol 1996, 62:71-82.

46. Sugawara Y, Azuma N, Onodera S, Tsunoka Y, Morimoto M: Th2 immune responses and alternatively activated macrophages (AAMacs) in helminth infection in aged mice. J Vet Med Sci 2011, 73(4):511-516.

47. Revaz-Breton M, Ronet C, Ives A, Torre YH, Masina S, Tacchini-Cottier F, Launois P: The MyD88 protein 88 pathway is differently involved in immune responses induced by distinct substrains of Leishmania major. Eur J Immunol 2010, 40(6):1697-707.

48. Chen L, Lei L, Chang X, Li Z, Lu C, Zhang X, Wu Y, Yeh IT, Zhong G: Mice deficient in MyD88 Develop a Th2-dominant response and severe pathology in the upper genital tract following Chlamydia muridarum infection. J Immunol 2010, 184(5):2602-1260.

49. Kane CM, Jung E, Pearce EJ: Schistosoma mansoni egg antigen-mediated modulation of Toll-like receptor (TLR)-induced activation occurs independently of TLR2, TLR4, and MyD88. Infect Immun 2008, 76(12):5754-5759.

50. Layland LE, Wagner $H$, da Costa CU: Lack of antigen-specific Th1 response alters granuloma formation and composition in Schistosoma mansoniinfected MyD88-/- mice. Eur J Immunol 2005, 35(11):3248-3257.

51. Helmby H, Grencis RK: Essential role for TLR4 and MyD88 in the development of chronic intestinal nematode infection. Eur J Immunol 2003, 33:2974-2979.

52. ML Manku H, Else KJ: The innate immune responses of colonic epithelial cells to Trichuris muris are similar in mouse strains that develop a type 1 or type 2 adaptive immune response. Infect Immun 2006, 74:6280-6286. 
53. Jenkins SJ, Allen JE: Similarity and diversity in macrophage activation by nematodes, trematodes, and cestodes. Journal of Biomedicine and Biotechnology 2010, 1-14.

54. Flynn RJ, Mulcahy G: Possible role for Toll-like receptors in Interaction of Fasciola hepatica excretory/secretory products with bovine macrophages. Infection and Immunity 2008, 678-684.

55. Guzmán-Morales J, Ariganello MB, Hammami I, Thibault M, Jolicoeur M, Hoemann CD: Biodegradable chitosan particles induce chemokine release and negligible arginase-1 activity compared to IL-4 in murine bone marrow-derived macrophages. Biochem Biophys Res Commun 2011, 405(4):538-544.

56. Sun C, Sun L, Ma H, Peng J, Zhen Y, Duan K, Liu G, Ding W, Zhao Y: The phenotype and functional alterations of macrophages in mice with hyperglycemia for long term. J Cell Physiol 2011.

57. Koide N, Mu MM, Hassan F, Islam S, Tumurkhuu G, Dagvadorj J, Naiki Y, Mori I, Yoshida T, Yokochi T: Lipopolysaccharide enhances interferongamma-induced nitric oxide (NO) production in murine vascular endothelial cells via augmentation of interferon regulatory factor-1 activation. J Endotoxin Res 2007, 13:167-175.

58. Dransfield I, Stephenson E, Haslett C: Recognition of apoptotic cells by phagocytes. In Techniques in Apoptosis: A User's Guide. Portland Press Ltd 1996, 149-174.

doi:10.1186/1471-2172-12-63

Cite this article as: Luo et al.: The absence of MyD88 has no effect on the induction of alternatively activated macrophage during Fasciola hepatica infection. BMC Immunology 2011 12:63.

\section{Submit your next manuscript to BioMed Central} and take full advantage of:

- Convenient online submission

- Thorough peer review

- No space constraints or color figure charges

- Immediate publication on acceptance

- Inclusion in PubMed, CAS, Scopus and Google Scholar

- Research which is freely available for redistribution

Submit your manuscript at www.biomedcentral.com/submit 